\title{
Solution structures of long-acting insulin analogues and their complexes with albumin
}

Ryberg, Line Abildgaard; Sønderby, Pernille; Barrientos, Fabian; Bukrinski, Jens T.; Peters, Günther H.J.; Harris, Pernille

Published in:

Acta crystallographica Section D: Structural biology

Link to article, DOI:

10.1107/S2059798318017552

Publication date:

2019

Document Version

Publisher's PDF, also known as Version of record

Link back to DTU Orbit

Citation (APA):

Ryberg, L. A., Sønderby, P., Barrientos, F., Bukrinski, J. T., Peters, G. H. J., \& Harris, P. (2019). Solution structures of long-acting insulin analogues and their complexes with albumin. Acta crystallographica Section $D$ : Structural biology , 75(3), 272-282. https://doi.org/10.1107/S2059798318017552

\section{General rights}

Copyright and moral rights for the publications made accessible in the public portal are retained by the authors and/or other copyright owners and it is a condition of accessing publications that users recognise and abide by the legal requirements associated with these rights.

- Users may download and print one copy of any publication from the public portal for the purpose of private study or research.

- You may not further distribute the material or use it for any profit-making activity or commercial gain

- You may freely distribute the URL identifying the publication in the public portal 
STRUCTURAL BIOLOGY

ISSN 2059-7983

Received 8 October 2018

Accepted 11 December 2018

Edited by M. Czjzek, Station Biologique de Roscoff, France

Keywords: SAXS; albumin; insulin analogues; protein complexes; rigid-body modelling; insulin detemir; insulin degludec.

Supporting information: this article has supporting information at journals.iucr.org/d

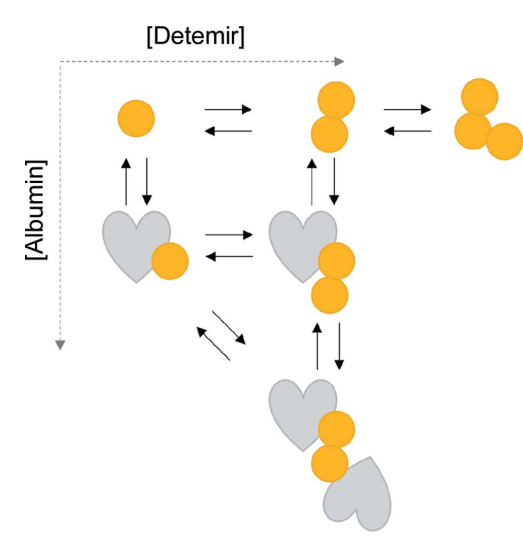

C 2019 International Union of Crystallography

\section{Solution structures of long-acting insulin analogues and their complexes with albumin}

\author{
Line A. Ryberg, ${ }^{a}$ Pernille Sønderby, ${ }^{a}$ Fabian Barrientos, ${ }^{a}$ Jens T. Bukrinski, \\ Günther H. J. Peters ${ }^{a}$ and Pernille Harris ${ }^{a}$ *
}

a Department of Chemistry, Technical University of Denmark, Kemitorvet Building 207, 2800 Kongens Lyngby, Denmark,
and ${ }^{\mathbf{b}} \mathrm{CMC}$ assist ApS, 2500 Copenhagen, Denmark. *Correspondence e-mail: ph@kemi.dtu.dk

The lipidation of peptide drugs is one strategy to obtain extended half-lives, enabling once-daily or even less frequent injections for patients. The half-life extension results from a combination of self-association and association with human serum albumin (albumin). The self-association and association with albumin of two insulin analogues, insulin detemir and insulin degludec, were investigated by small-angle X-ray scattering (SAXS) and dynamic light scattering (DLS) in phenolic buffers. Detemir shows concentration-dependent self-association, with an equilibrium between hexamer, dihexamer, trihexamer and larger species, while degludec appears as a dihexamer independent of concentration. The solution structure of the detemir trihexamer has a bent shape. The stoichiometry of the association with albumin was studied using DLS. For albumin-detemir the molar stoichiometry was determined to be $1: 6$ (albumin:detemir ratio) and for albumin-degludec it was between 1:6 and 1:12 (albumin:degludec ratio). Batch SAXS measurements of a 1:6 albumin:detemir concentration series revealed a concentration dependence of complex formation. The data allowed the modelling of a complex between albumin and a detemir hexamer and a complex consisting of two albumins binding to opposite ends of a detemir dihexamer. Measurements of size-exclusion chromatography coupled to SAXS revealed a complex between a degludec dihexamer and albumin. Based on the results, equilibria for the albumin-detemir and albumin-degludec mixtures are proposed.

\section{Introduction}

Human serum albumin (albumin) comprises more than half of the total amount of protein in the blood plasma, with a concentration of $35-50 \mathrm{mg} \mathrm{ml}^{-1}$. Albumin has many important physiological functions involving regulation of the colloidal osmotic pressure and the transport of a variety of ligands such as physiological metabolites, fatty acids, hormones, bile acids and drugs (Fanali et al., 2012; Ha \& Bhagavan, 2013; Yang et al., 2014). Albumin has a half-life of approximately 19 days (Peters, 1985) that arises from binding to the major histocompatibility complex-related Fc receptor for immunoglobulin $\mathrm{G}(\mathrm{FcRn})$, resulting in a $\mathrm{pH}$-dependent recycling mechanism. Albumin is thus rescued from degradation in the same manner as immunoglobulin $\mathrm{G}$ (Chaudhury et al., 2003, 2006).

These pharmacokinetic properties are exploited by using albumin as a vehicle for drug delivery to increase the half-life of fast-degrading peptides and other smaller molecules. Halflife extension can be obtained by the chemical conjugation of a drug to albumin (Bukrinski et al., 2017) or by noncovalent complexation. One widely applied strategy to obtain 
complexation is lipidation, which exploits the natural affinity of albumin for fatty acids (Sleep, 2014; Sleep et al., 2013). Examples of such molecules are the lipidated insulins detemir and degludec (trade names Levemir ${ }^{\mathbb{R}}$ and Tresiba ${ }^{\mathbb{R}}$, respectively; Novo Nordisk A/S) and the lipidated glucagon-like peptide-1 analogues liraglutide and semaglutide (trade names Victoza ${ }^{\mathbb{R}}$ and Saxenda ${ }^{\mathbb{R}}$, and Ozempic ${ }^{\mathbb{R}}$, respectively; Novo Nordisk A/S).

Detemir and liraglutide are examples of first-generation lipidated peptides; the half-life of detemir is 5-7 h (Danne et al., 2003) and that of liraglutide is $13 \mathrm{~h}$ (Knudsen et al., 2000). Optimization of the fatty acids led to the second-generation products degludec and semaglutide. The half-life of degludec is $25 \mathrm{~h}$ (Heise et al., 2012), while that of semaglutide is approximately one week (Lau et al., 2015). The extremely long half-life of semaglutide indicates that the albumin-semaglutide complex is so strong that it allows the semaglutidealbumin complex to be recycled, mediated by the FcRn receptor.

Apart from complexation with albumin, lipidation can lead to self-assembly of the peptides in the subcutaneous depot, resulting in slower diffusion into the bloodstream (Havelund et al., 2004) or to oligomers circulating in the blood (Frederiksen et al., 2015). The overall mechanism whereby the peptides obtain a longer half-life is a combination of these two effects, complexation to albumin and oligomerization, where the importance of each effect differs from peptide to peptide (Deacon, 2009; Agers $\varnothing$ et al., 2002; Jonassen et al., 2012; European Medicines Agency, 2012; Havelund et al., 2004).

In this study, we use detemir and degludec as models to investigate the binding of a first-generation and a secondgeneration lipidated peptide. Both insulins are used in the treatment of diabetes mellitus type 1 and type 2 , and both are long-acting lipidated insulin analogues that are used as basal insulin to control blood sugar levels during fasting. A basal insulin is combined with a rapid-acting insulin used in connection with a meal to mimic the nondiabetic response to energy uptake.

The crystal structure of detemir in the presence of phenol was determined by Whittingham et al. (1997). The crystal structure shows that detemir forms dihexamers stabilized by fatty-acid interactions at the hexamer interface. Whether the fatty-acid interactions are present in solution or simply an artefact induced by crystal packing is not clear (Whittingham et al., 1997). In solution, detemir has previously been shown to exist in an equilibrium between hexamers and dihexamers (Havelund et al., 2004), and a recent study using analytical ultracentrifugation sedimentation velocity showed that detemir is present in an equilibrium between monomers, hexamers, dihexamers and trihexamers (Adams et al., 2018).

The binding of detemir to albumin and its mechanism of protraction was studied by Havelund and coworkers using size-exclusion chromatography (SEC). They found that albumin binds to both dimeric and hexameric detemir and concluded that both the oligomerization into dihexamers and the interaction with albumin contributed to the prolonged half-life (Havelund et al., 2004).
Table 1

Overview of the buffers, listing their constituents, $\mathrm{pH}$ and ionic strength (IS).

\begin{tabular}{|c|c|c|c|}
\hline Buffer & Constituents & $\mathrm{pH}$ & IS $(\mathrm{m} M)$ \\
\hline Buf $_{\text {det }}$ & 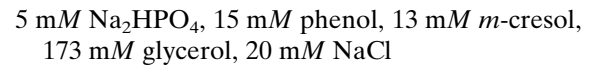 & 7.4 & 31 \\
\hline Buf $_{\text {alb-det }}$ & $\begin{array}{l}\text { 5-10 } \mathrm{m} M \mathrm{Na}_{2} \mathrm{HPO}_{4}, 10-13 \mathrm{~m} M \mathrm{~m} \text {-cresol, } \\
11-15 \mathrm{~m} M \text { phenol, } 130-171 \mathrm{~m} M \text { glycerol, } \\
\text { 24-69 } \mathrm{m} M \mathrm{NaCl}\end{array}$ & 7.4 & $36-89$ \\
\hline Buf $_{\text {deg }}$ & $\begin{array}{l}25 \mathrm{~m} M \mathrm{Na}_{2} \mathrm{HPO}_{4}, 16 \mathrm{~m} M m \text {-cresol, } 16 \mathrm{~m} M \text { phenol, } \\
213 \mathrm{~m} M \text { glycerol, } 20 \mathrm{mM} \mathrm{NaCl}\end{array}$ & 7.6 & 76 \\
\hline
\end{tabular}

The solution structure of degludec has been studied by both small-angle X-ray scattering (SAXS; Steensgaard et al., 2013) and analytical ultracentrifugation (Adams et al., 2017, 2018; Steensgaard et al., 2013). While there is general agreement that degludec is found as a dihexamer in phenol-containing solutions, different crystal forms show ambiguous intermolecular contacts (Steensgaard et al., 2013).

The binding of degludec to albumin and self-association was studied by Jonassen et al. (2012) using SEC. They found that degludec binds to albumin with a 2.4-fold higher affinity than detemir and forms multihexamers in phenol-free buffer with $\mathrm{Zn}^{2+}$. The protracted action of degludec mainly results from multihexamerization in the subcutaneaous depot (Kurtzhals et al., 2011; Seested et al., 2012; Jonassen et al., 2012) and also to some extent from albumin binding (European Medicines Agency, 2012).

Using SAXS in combination with dynamic light scattering (DLS), we have studied the solution structures of detemir and degludec alone and in complex with albumin. To our knowledge, these are the first SAXS studies of detemir alone and of albumin-detemir and albumin-degludec complexes.

\section{Materials and methods}

\subsection{Materials}

Proteins were obtained as commercially available products: insulin detemir (detemir) as Levemir ${ }^{\circledR}$ and insulin degludec (degludec) as Tresiba ${ }^{\circledR}$, both from Novo Nordisk A/S, and recombinant human serum albumin as Recombumin ${ }^{\mathbb{R}}$ Alpha or Recombumin ${ }^{\circledR}$ Elite (formally named AlbIX $^{\circledR}$ ) from Albumedix Ltd.

\subsection{SAXS sample preparation}

The insulin analogues detemir and degludec were measured alone and in a mixture. An overview of the samples is given in Supplementary Table S1. All protein samples were dialyzed over three shifts using Slide-A-Lyzer ${ }^{\mathbb{R}}$ Dialysis Cassettes from Thermo Scientific. The buffer from the last shift was sterilefiltered using a $0.2 \mu \mathrm{m}$ filter and used for sample-dilution and buffer measurements. All of the buffers that were used are listed in Table $1.1 \mathrm{kDa}$ cutoff spin filters were used for concentration. If possible, protein concentrations were determined by UV-Vis spectroscopy using a NanoDrop ${ }^{\mathbb{R}} 1000$ spectrophotometer from Thermo Scientific. The extinction coefficient for albumin was estimated from the sequence as 
Table 2

Experimental setup of SAXS experiments.

\begin{tabular}{lll}
\hline & I911-SAXS, MAX II, & P12, PETRA III, \\
Instrument & MAX IV Laboratory & DESY \\
\hline Detector & PILATUS 1M & PILATUS 2M \\
Wavelength $(\AA)$ & 0.9100 & 1.241 \\
$q$-range $\left(\mathrm{nm}^{-1}\right)$ & $0.0829-5.406$ & $0.0248-5.036$ \\
Exposure time $(\mathrm{s})$ & $4 \times 30$ & $20 \times 0.05$ \\
Temperature $(\mathrm{K})$ & 293 & 293 \\
Sample-to-detector distance $(\mathrm{mm})$ & 1962.110 & 3000 \\
\hline
\end{tabular}

$34445 \mathrm{M}^{-1} \mathrm{~cm}^{-1}$ at $280 \mathrm{~nm}$ using the ProtParam (Gasteiger $e t$ al., 2005) tool from ExPaSy (Gasteiger et al., 2003). For protein stocks containing phenol or $m$-cresol, the concentrations were determined by scaling to SAXS data at a known concentration or by refractometry using an Anton Paar Abbemat 550 refractometer with a refractive-index increment, $\mathrm{d} n / \mathrm{d} c$, of $0.19 \mathrm{ml} \mathrm{g}^{-1}$.

\subsection{SAXS data collection}

SAXS experiments were carried out on the I911-SAXS beamline (Labrador et al., 2013) at the MAX IV Laboratory, Lund, Sweden and on the EMBL P12 BioSAXS beamline (Blanchet et al., 2015) at PETRA III, DESY, Hamburg, Germany. Data-collection parameters are given in Table 2. The sample-to-detector distance and the direct beam position were calibrated using silver behenate, and water was measured to place the data on an absolute scale. The buffer was measured before and after each sample.

\subsection{SEC-SAXS data collection}

UV-SEC-SAXS measurements were carried out on the EMBL P12 BioSAXS beamline (Blanchet et al., 2015) at DESY using the experimental setup described in Table 2. A Superdex 200 Increase 10/300 GL column (GE Healthcare Life Sciences) was used in combination with an Agilent 1260 Infinity Bio-Inert HPLC/FPLC machine with elution through a UV-Vis spectrophotometer and thereafter directly to the P12 beamline. $100 \mu \mathrm{l}$ of sample was injected and the flow rate

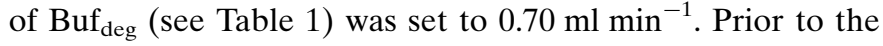
measurements, the column was equilibrated with eight column volumes.

\subsection{SAXS data analysis and modelling}

For data collections at the MAX IV Laboratory, all calibrations, corrections and data reduction were carried out using the PyFAI package (Kieffer \& Wright, 2013). Buffer averaging and subtraction were performed in PRIMUSqt (Konarev et al., 2003). For the data collected at EMBL, an automated pipeline (Blanchet et al., 2015) carried out all data processing and additionally provided preliminary data analysis. For the SEC-SAXS data, CHROMIXS (Franke et al., 2017) was used in automated mode to select buffer and sample regions and to perform buffer subtraction. For all SAXS curves the scattering vector is defined as $q=4 \pi \sin \theta / \lambda$, where $2 \theta$ is the scattering angle and $\lambda$ is the wavelength.
The ATSAS program package v.2.8.3 (Franke et al., 2017) was used for data analysis and modelling. The baselinesubtracted SAXS curves were investigated for inter-particle interference by Guinier analysis in PRIMUSqt (Konarev et al., 2003) and were truncated at low $q$ values if necessary. Pair distance distribution functions $[P(r)$ functions] were calculated by GNOM (Svergun, 1992). Molecular parameters were obtained from Guinier analysis and calculated $P(r)$ functions. Molecular masses (MMs) were calculated as $\mathrm{MM}=\left[N_{\mathrm{A}} I(0) / c\right] /$ $\Delta \rho_{\mathrm{M}}^{2}$, where $I(0) / c$ is the concentration-normalized forward scattering, $N_{\mathrm{A}}$ is the Avogadro constant and $\Delta \rho_{\mathrm{M}}$ is the scattering contrast per mass. The average partial specific volume for proteins of $0.7425 \mathrm{~cm}^{3} \mathrm{~g}^{-1}$ determined by Mylonas $\&$ Svergun (2007) was used to calculate $\Delta \rho_{\mathrm{M}}$. The MM in $\mathrm{kDa}$ was, furthermore, estimated from the Porod volume $\left(V_{\mathrm{p}}\right)$ in $\mathrm{nm}^{3}$ by the relation $V_{\mathrm{p}} / \mathrm{MM}=1.50$ (Trewhella et al., 2017).

Prior to ab initio modelling, AMBIMETER (Petoukhov \& Svergun, 2015) was run in order to assess the ambiguity of the modelling. DAMMIF (Franke \& Svergun, 2009) was used to calculate $a b$ initio models in interactive mode with a dummyatom radius of $2.7 \AA$ and standard settings unless otherwise specified. To generate models with $P 2$ symmetry, DAMMIN (Svergun, 1999) was used with prolate anisometry across the symmetry axis. DAMMIN was used because it is not possible to specify a direction of anisometry with $D A M M I F$, and the models that were generated without constraining it resulted in an undesired direction of symmetry. For each curve, 20 models were calculated; they were subsequently aligned and averaged using the DAMAVER program suite (Volkov \& Svergun, 2003) and clustered using DAMCLUST (Petoukhov et al., 2012). The resolution of the models was determined using SASRES (Tuukkanen et al., 2016). The most typical model of the ensemble or a cluster was chosen as the representative.

For rigid-body modelling, SASREFCV (Petoukhov \& Svergun, 2005, 2006; SASREF) was run using standard settings for X-ray data on the first $80 \%$ of the scattering curve. The fits of the models to the experimental data were calculated with CRYSOL (Svergun et al., 1995) using 500 points in the theoretical curve and fitting up to $q_{\max }=0.4 \AA^{-1}$ with constant background subtraction. The subunits used in rigidbody modelling were crystal structures downloaded from the Protein Data Bank (PDB).

Both insulin and albumin exist in different conformations. Albumin changes conformation upon the binding of fatty acids (Ascenzi \& Fasano, 2010), while insulin and detemir (Olsen \& Kaarsholm, 2000) hexamers can exist in $R_{6}, T_{3} R_{3}$ or $\mathrm{T}_{6}$ conformations depending on the binding of phenolic ligands. Therefore, a fatty-acid-free (PDB entry 1ao6; Sugio et al., 1999) and a fatty-acid-bound albumin structure (PDB entry 1bj5; Curry et al., 1998) were used in combination with $\mathrm{R}_{6}, \mathrm{~T}_{3} \mathrm{R}_{3}$ and $\mathrm{T}_{6}$ insulin hexamers [PDB entries 1ev3 (Smith et al., 2000), 1 trz (Ciszak \& Smith, 1994) and 1mso (Smith et al., 2003), respectively]. The insulin crystal structures are not lipidated, and it is assumed that the effect of lipidation is negligable in rigid-body modelling. When necessary, symmetry operations were applied to the structures to generate hexamers. To generate dihexamers, the hexamers were trans- 
lated along the $z$ axis in steps of $0.1 \AA$. The dihexamers were fitted to the degludec data with CRYSOL in order to determine the conformation and the optimal inter-hexameric distance. The best fit was obtained with an $R_{3} T_{3}-T_{3} R_{3}$ dihexamer at an inter-hexameric distance of $35.4 \AA$ (Supplementary Fig. S1), which is in agreement with previous findings by Steensgaard et al. (2013). The different insulin conformations were not distinguishable in the rest of the data and resulted in very similar fits. Based on this, the models generated with the $T_{3} R_{3}$ hexamer and the $R_{3} T_{3}-T_{3} R_{3}$ dihexamer were used. Likewise, the models generated with fatty-acid-free and fatty-acid-bound albumin showed similar fits to the data. We chose to use the models generated with fatty-acid-bound albumin, as we expect the binding of detemir and degludec to induce a conformational change similar to that induced by fatty-acid binding since both insulin analogues are lipidated.

Details of the generated $a b$ initio and rigid-body models are reported in Supplementary Table S8 in the format proposed by the updated SAXS publication guidelines (Trewhella et al., 2017). The $a b$ initio modelling is also described in further detail in the supporting information. Both SAXS data and models have been deposited in the Small Angle Scattering Biological Database (see Table S8; https://www.sasbdb.org/; Valentini et al., 2015).

SEC-SAXS was not available at the time of the detemir experiments, and the modelling was performed on polydisperse data. OLIGOMER (Konarev et al., 2003) was used to estimate the volume fractions of the different species in the samples with a form-factor file as input. The file was produced by FFMAKER (Konarev et al., 2003) using CRYSOL with standard settings and 256 points in the theoretical scattering curve. For the albumin-detemir samples, the molar stoichiometries were used as constraints in FFMAKER. OLIGOMER was run with a maximum scattering vector $q_{\max }=0.4 \AA^{-1}$ and the addition of a constant component. The structures used as input were albumin, insulin monomer, dimer, hexamer and dihexamer, and the rigid-body models of the insulin trihexamer, albumin-hexamer, albumin-dihexamer and albumindihexamer-albumin complexes.

\subsection{DLS data collection and analysis}

DLS experiments were carried out to determine the stoichiometries of the albumin-detemir and albumin-degludec complexes. Albumin was mixed with detemir and degludec, respectively, while keeping the total protein mass concentration constant. The mole fraction of albumin was calculated by treating the detemir/degludec hexamer as an entity.

For the albumin-detemir samples, a total protein concentration of $14.2 \mathrm{mg} \mathrm{ml}^{-1}$ was used. For the albumin-degludec samples, a total protein concentration of $10 \mathrm{mg} \mathrm{ml}^{-1}$ was used.

A DynaPro DLS plate reader (Wyatt Technology, Santa Barbara, California, USA) was used for the measurements and the Wyatt DYNAMICS software was used for data collection and analysis. $100 \mu \mathrm{l}$ of each sample was loaded onto a 96-well nonbinding Corning ${ }^{\mathrm{R}}$ microplate and centrifuged for $2 \mathrm{~min}$ at $2000 \mathrm{rev} \mathrm{min}^{-1}$ to remove air bubbles. Each sample was measured ten times for $5 \mathrm{~s}$. The measurements were carried out at $298 \mathrm{~K}$ and in triplicate. The viscosities and the refractive indices of the solvents were calculated using the Zetasizer software v.7.1 (Malvern Instruments, Worcestershire, England) and used in data analysis. $Z$-average sizes obtained by cumulants analysis are reported in the results.

\subsection{Figures}

All figures were prepared using PyMOL (v.1.8.2.3; Schrödinger) and all plots were prepared by MATLAB (v.9.1; The MathWorks, Natick, Massachusetts, USA).

\section{Results}

\subsection{SAXS insulin oligomers}

The scattering curves from the concentration series of detemir and degludec are presented in Fig. 1. Molecular

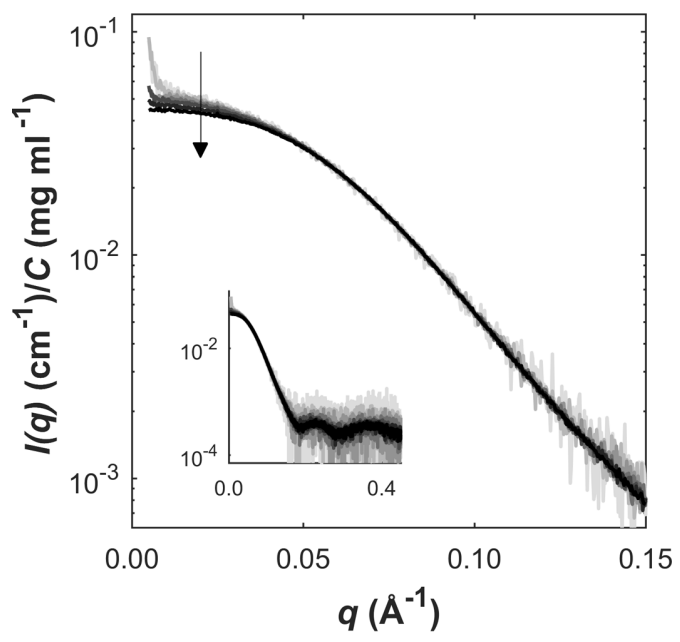

(a)

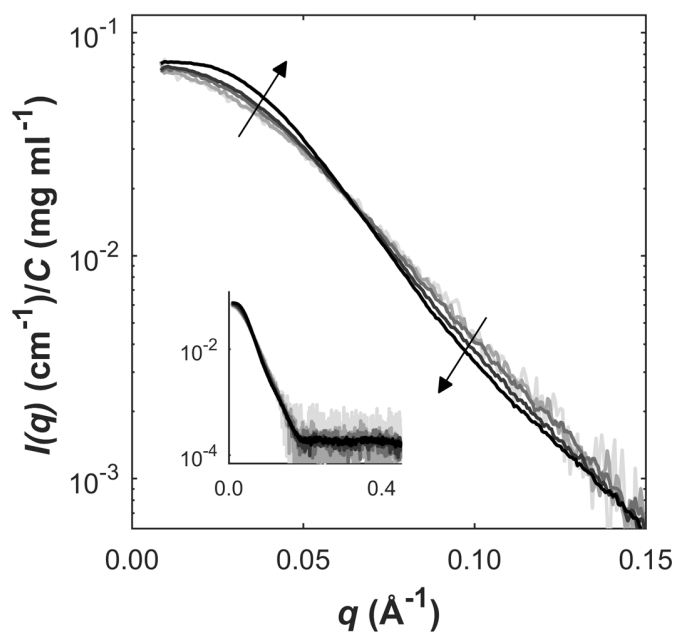

Figure 1

(b)

Scattering curves, normalized for concentration, of $(a)$ degludec $(0.5-$ $\left.7.7 \mathrm{mg} \mathrm{ml}^{-1}\right)$ and $(b)$ detemir $\left(0.5-9.9 \mathrm{mg} \mathrm{ml}^{-1}\right)$; darker shades correspond to higher concentrations. The arrows illustrate changes with increasing concentration. 
Table 3

OLIGOMER results for detemir samples.

Results are for detemir samples in the concentration range $0.5-2.5 \mathrm{mg} \mathrm{ml}^{-1}$, showing volume fractions of the species with uncertainties in the last digit in parentheses and $\chi^{2}$ fits to experimental data.

\begin{tabular}{lllll}
\hline Concentration $\left(\mathrm{m} \mathrm{ml}^{-1}\right)$ & $\chi^{2}$ & Hexamer & Dihexamer & Trihexamer \\
\hline 0.5 & 0.64 & $0.07(3)$ & $0.13(3)$ & $0.80(3)$ \\
1.0 & 0.66 & $0.05(1)$ & $0.10(2)$ & $0.85(1)$ \\
2.5 & 1.23 & & $0.016(5)$ & $0.984(5)$ \\
\hline
\end{tabular}

parameters were derived from the curves and are presented in Supplementary Tables S2 and S3.

3.1.1. Degludec. For the degludec curves, we observed no concentration-dependent change in the overall curve shape $\left(q \geq 0.04 \AA^{-1}\right.$; Fig. 1a). For $q<0.04 \AA^{-1}$ a decrease in the normalized forward scattering $[I(0) / c]$ was observed with increasing protein concentration, indicating repulsion. To obtain an ideal scattering curve, low- and high-concentration data were merged to avoid repulsion artefacts at high concentrations. The SAXS-derived MM ranges from 12 to 13 monomers, corresponding to a dihexamer (Supplementary Fig. S1).

3.1.2. Detemir. For the detemir curves, we observed an increase in curve steepness from $q=0.05$ to $0.12 \AA^{-1}$ with increasing concentration (Fig. 1b). The change in the shape of the curve indicates concentration-dependent oligomerization. Repulsion was observed at higher concentrations as a flattening of the curves for low $q$ values. MM ranges from 17 to 22 monomers, and the increase is consistent with an increase in the Porod volume (Supplementary Table S3).
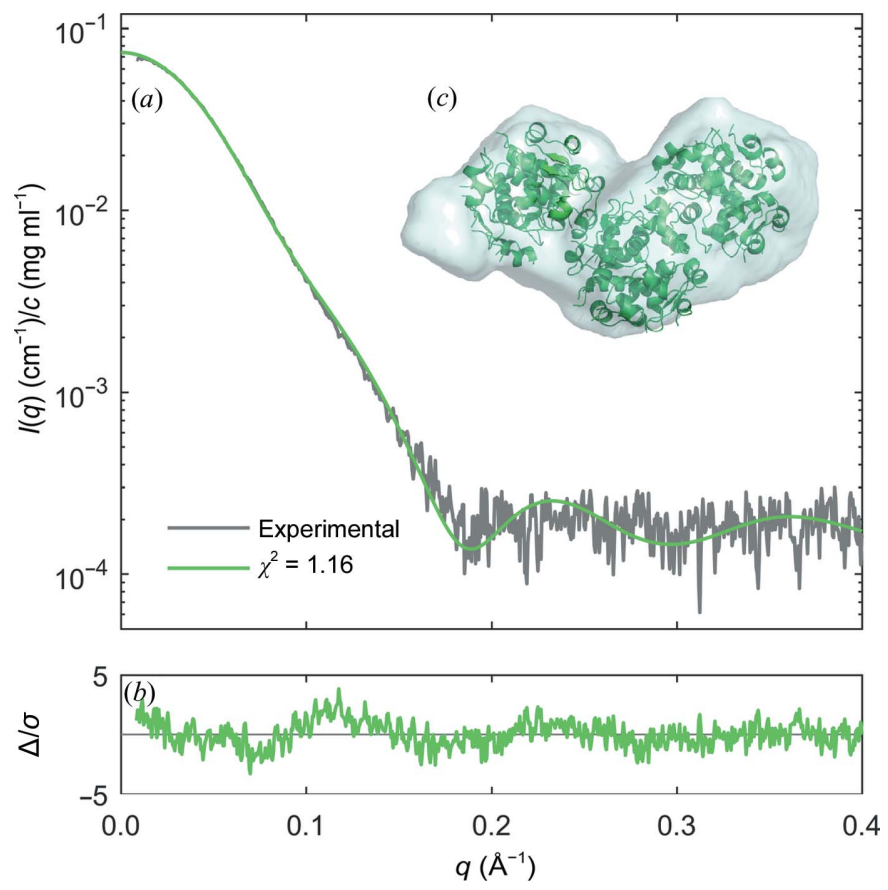

Figure 2

Modelling results of the detemir trihexamer based on the $2.5 \mathrm{mg} \mathrm{ml}^{-1}$ detemir scattering curve. (a) Fit of the rigid-body model (green) to the experimental data (grey). (b) shows an error-weighted residual plot of the model. (c) The rigid-body model (green) is superimposed onto the lowresolution $a b$ initio model (light blue).
Until recently, the highest oligomer of detemir reported was a dihexamer in equilibrium with a hexamer (Havelund et al., 2004), but in 2018 Adams and coworkers reported detemir in a trihexameric state in equilibrium with monomers, hexamers and dihexamers (Adams et al., 2018).

We chose the $2.5 \mathrm{mg} \mathrm{ml}^{-1}$ curve for modelling the detemir trihexamer as it was unaffected by repulsion and had an MM close to that expected for a trihexamer. Ten rigid-body models were generated by $S A S R E F$ with three hexamers as input. In Fig. 2, the best model is superimposed onto the representative $a b$ initio model generated by $D A M M I F(42 \pm 3 \AA$ resolution $)$. The $a b$ initio and rigid-body models overlap nicely, which gives confidence in the modelled trihexamer. The model fits the data well, with $\chi^{2}=1.16$ (Fig. $2 a$ ).

To assess the equilibria in the concentration series, we ran $O L I G O M E R$ with PDB structures of the insulin monomer, dimer, hexamer and dihexamer, and the model of the trihexamer. The results are presented in Table 3 and the fits to the experimental data are shown in Fig. 3. The lower concentration samples, 0.5 and $1.0 \mathrm{mg} \mathrm{ml}^{-1}$, consist of an equilibrium between hexamer, dihexamer and trihexamer. The
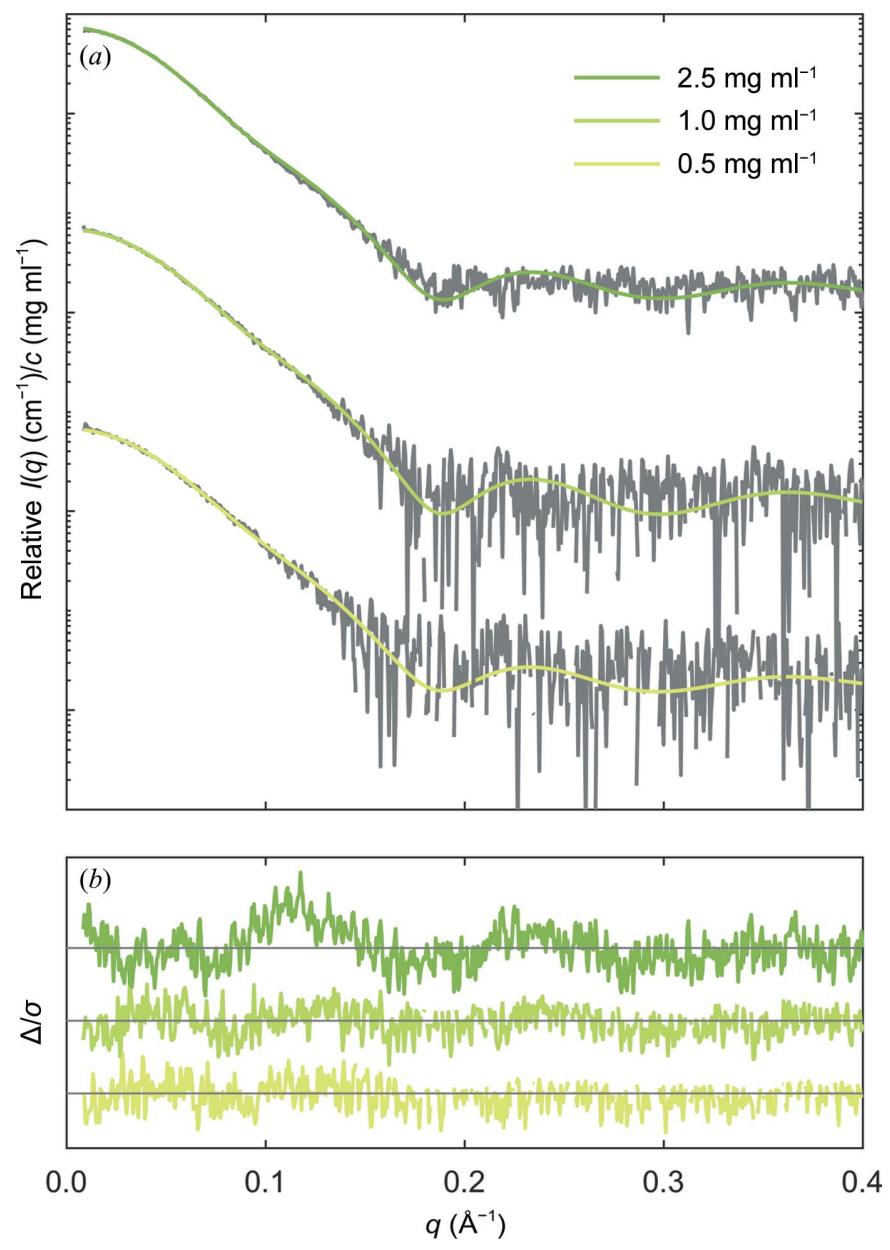

Figure 3

OLIGOMER results for detemir samples in the concentration range $0.5-$ $2.5 \mathrm{mg} \mathrm{m}^{-1}$. (a) OLIGOMER fits are plotted (green; darker shades correspond to higher concentrations) with the experimental scattering curves (grey). The scattering curves have been shifted on the $I(q) / c$ axis for clarity. (b) shows an error-weighted residual plot of the fits. 
$2.5 \mathrm{mg} \mathrm{ml}^{-1}$ curve is almost monodisperse, with $98.4 \%$ trihexamer and $1.6 \%$ dihexamer. For the higher concentration samples, the OLIGOMER results do not fit the experimental data (data not shown), reflecting that higher oligomers are needed to describe the data. This is supported by a steeper decrease in their scattering curves around $q=0.05-0.10 \AA^{-1}$ in Fig. 1(b).

\subsection{DLS of albumin complexes}

DLS experiments were set up to determine the binding stoichiometry between albumin and detemir and degludec, respectively. In the experiments, the mass fraction was varied, the molar stoichiometry was calculated and the maximum measured radius of hydration $\left(R_{\mathrm{h}}\right)$ was considered to represent the stoichiometry of the protein complex (Hanlon et al., 2010).

The results are presented in Fig. 4, in which selected molar ratios are marked on the top $x$ axis. For detemir, a peak in $R_{\mathrm{h}}$ is observed close to a 1:6 molar ratio. For degludec, the maximum in $R_{\mathrm{h}}$ is more flat and is observed between ratios of $1: 12$ and $1: 6$.

\subsection{Albumin-degludec complex structure}

Based on the maximum in $R_{\mathrm{h}}$ between molar ratios of 1:6 and 1:12, albumin-degludec complex formation was investigated at both ratios. The scattering curves of the albumindegludec mixtures are shown in Fig. 5 and their SAXS-derived

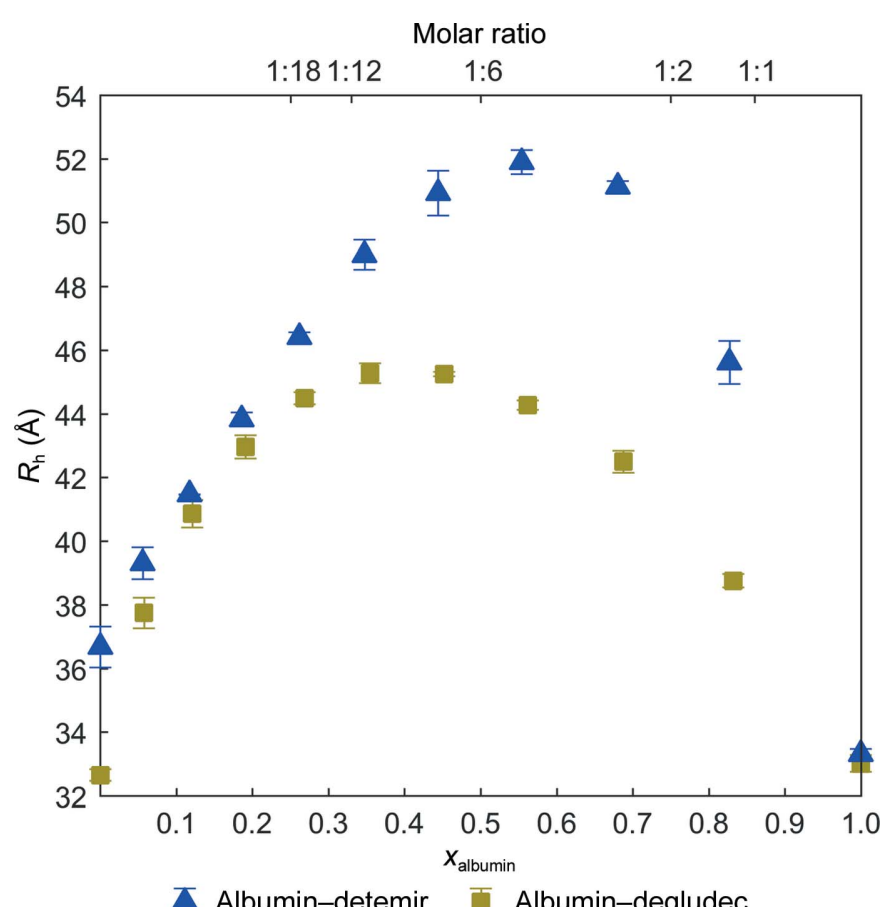

Figure 4

Results of DLS experiments on albumin-detemir (blue triangles) and albumin-degludec (olive squares) mixtures. The average hydrodynamic radius is plotted as a function of the molar fraction of albumin in the mixtures. The upper $x$ axis indicate the molar ratio between albumin and either detemir or degludec. The error bars represent standard deviations. molecular parameters are given in Supplementary Tables S4 and S5.

The shapes of the scattering curves for the 1:12 mixtures (Fig. 5a) do not change with protein concentration. The MM values derived from the data were $138-141 \mathrm{kDa}$, corresponding to a monodisperse 1:12 complex $(\mathrm{MM}=140 \mathrm{kDa})$.

The overall shape of the 1:6 scattering curves (Fig. 5b) also does not change with concentration, except for an increase in $I(0) / c$ corresponding to attractive interactions at higher concentrations. The MM values derived from the 1:6 data range between 145 and $163 \mathrm{kDa}$; they do not correspond directly to monodisperse $1: 6,1: 12$ or $2: 12$ complexes (MM values of 103,140 and $206 \mathrm{kDa}$, respectively), but rather to a mixture of different species. In order to separate the species, a SEC-SAXS experiment was conducted.

The SAXS intensity trace of the SEC-SAXS run is shown in Fig. 6(a) with two apparent peaks. The scattering curve of the

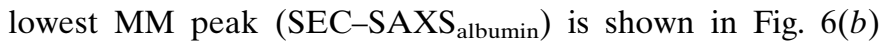
and overlaps very well with a batch SAXS measurement of albumin. The scattering curve of the higher MM peak

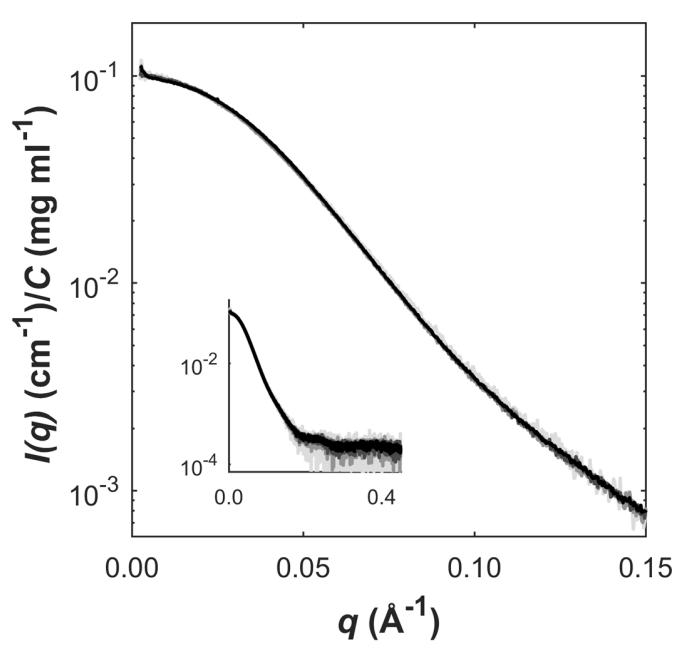

(a)

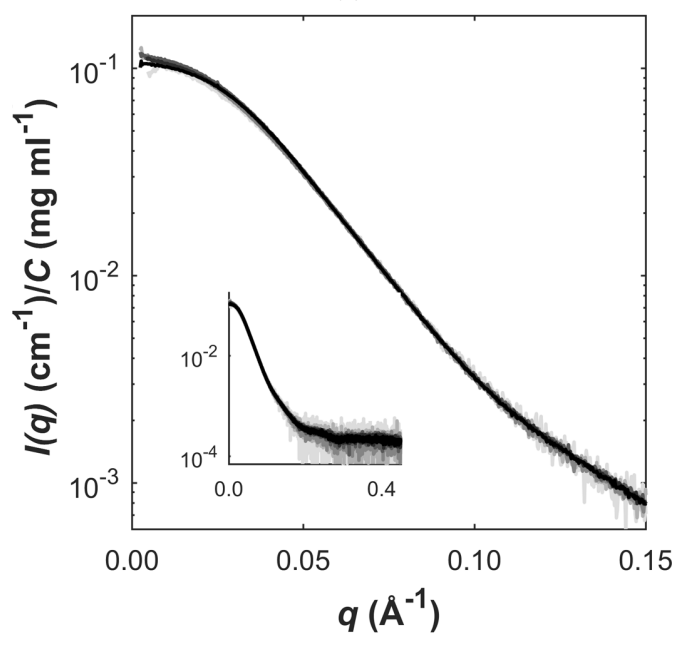

Figure 5

(b)

Scattering curves, normalized for concentration, of albumin and degludec mixed in (a) 1:12 and (b) 1:6 ratios; darker shades correspond to higher concentrations. 


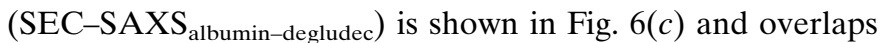
very well with a 1:12 albumin-degludec batch SAXS measurement. The MM value derived from the curve is $141 \mathrm{kDa}$, which could correspond to an albumin-dihexamer or a hexamer-albumin-hexamer complex (both with an MM of $140 \mathrm{kDa}$ ). These complexes will be modelled in the following section based on the SEC-SAXS albumin-degludec $_{\text {curve. }}$

In addition to the two apparent peaks in the chromatogram, a small shoulder consisting of two peaks is present on the left

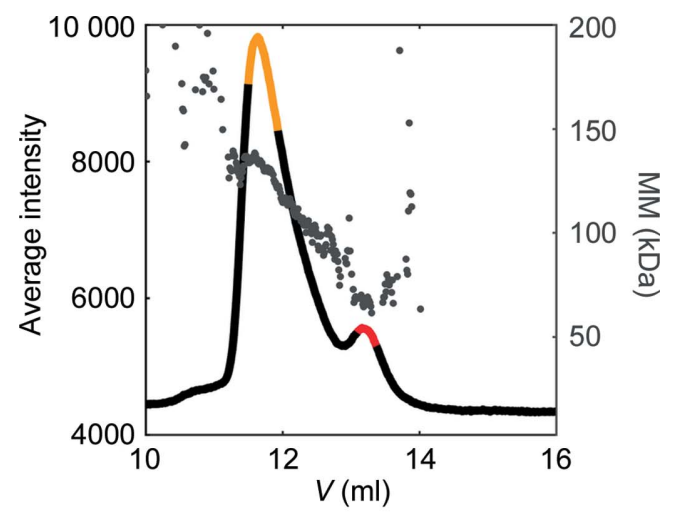

(a)

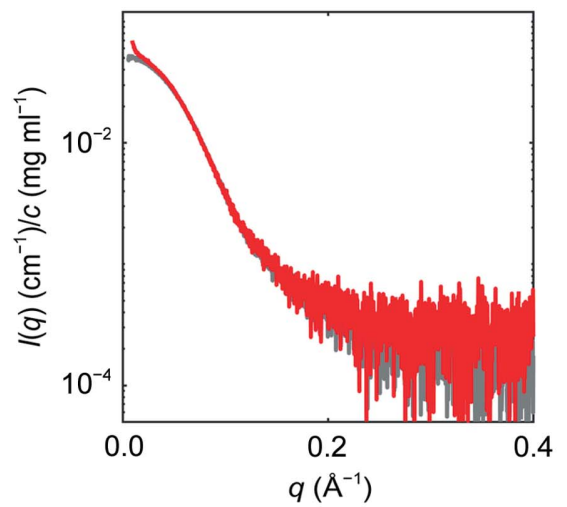

(b)

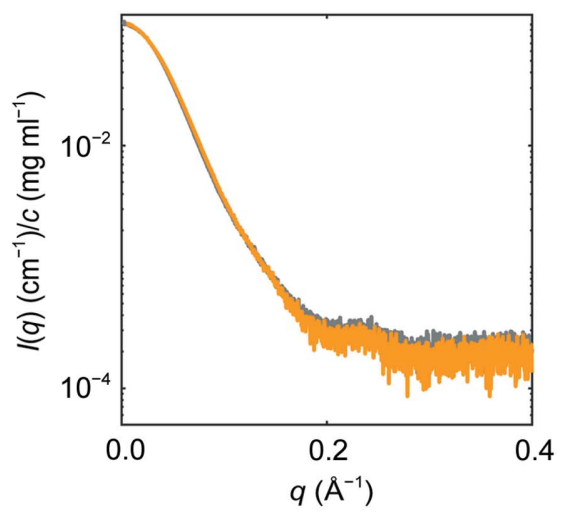

(c)

Figure 6

SEC-SAXS results for albumin and degludec mixed in a 1:6 ratio. (a) Plot showing average intensity and $\mathrm{MM}$ as a function of column volume, with peaks marked in yellow and red. (b) Scattering curve (SEC-SAXS albumin $)$ of the peak at $\sim 13.2 \mathrm{ml}$ (red) shown with a batch scattering curve for albumin at $2.8 \mathrm{mg} \mathrm{ml}^{-1}$ (grey). (c) Scattering curve (SEC-SAXS albumin $_{\text {) of }}$ the peak at $\sim 11.7 \mathrm{ml}$ (yellow) and a batch scattering curve for albumindegludec in a 1:12 ratio at $6.5 \mathrm{mg} \mathrm{ml}^{-1}$ (grey). All scattering curves are normalized for concentration. side of the main peak, which explains the higher MM for the 1:6 mixture and corresponds to larger protein complexes.

3.3.1. Rigid-body modelling of the albumin-dihexamer complex. Ten rigid-body models were generated by $S A S R E F$ based on the SEC-SAXS albumin-degludec $_{\text {curve with albumin and }}$ two hexamers as input in order to test whether the hexamers bind albumin separately or as a dihexamer. We found that the hexamers in the best-fitting model formed a dihexamer, thus suggesting an albumin-dihexamer complex. Ten rigid-body models were therefore generated with albumin and a dihexamer as input. The best of these ten models fitted the data well with $\chi^{2}=1.74$ (Fig. $7 a$ ) and showed good agreement with the representative $a b$ initio model generated by DAMMIF $(41 \pm$ $3 \AA$ resolution; Fig. 7c). In the complex, the dihexamer binds close to Sudlow's site I, which is one of the major drug-binding sites in albumin and overlaps with fatty-acid-binding site 7 (FA7; Sudlow et al., 1975).

\subsection{Albumin-detemir complex structures}

The scattering curves of the albumin-detemir samples are shown in Supplementary Fig. S2. Clearly, the curves are affected by concentration-dependent equilibria.

Two of the obtained SAXS curves were used for modelling: the $8.5 \mathrm{mg} \mathrm{ml}^{-1}$ SAXS curve with an MM of $104 \mathrm{kDa}$, which could correspond to an albumin-hexamer complex (MM of $102 \mathrm{kDa}$ ), and the $15.6 \mathrm{mg} \mathrm{ml}^{-1} \mathrm{SAXS}$ curve with an MM of $213 \mathrm{kDa}$, which could correspond to an albumin-dihexameralbumin complex (MM of $204 \mathrm{kDa}$ ). These curves are shown in Fig. 8.
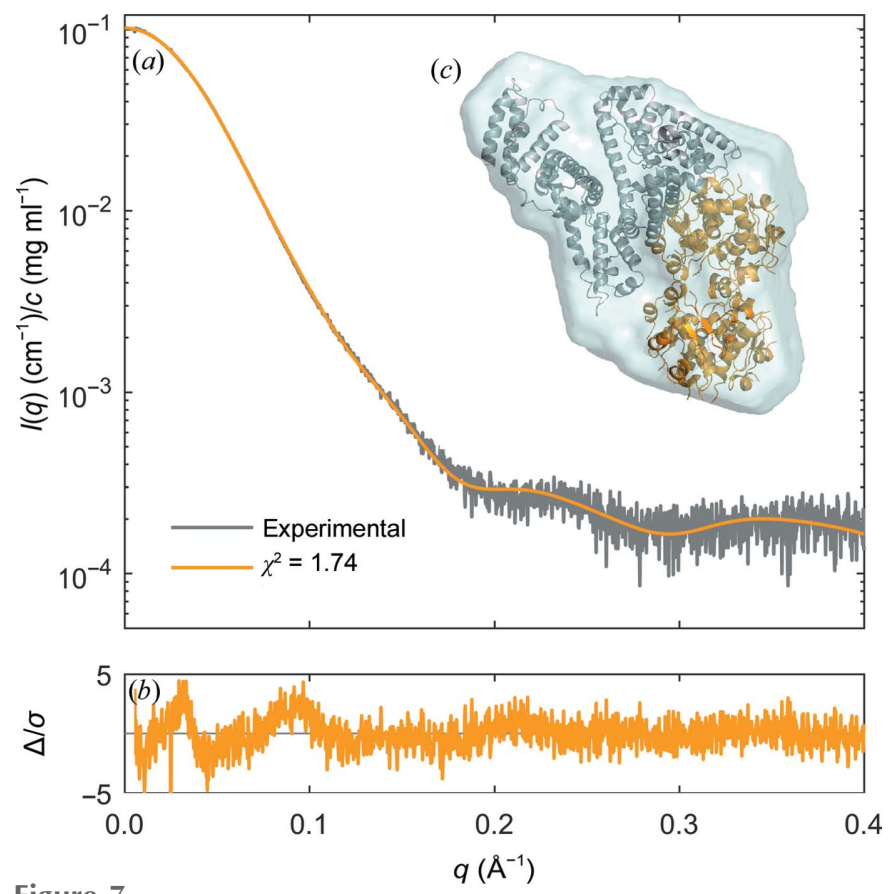

Figure 7

Modelling results of the albumin-dihexamer complex based on the SEC$\mathrm{SAXS}_{\text {albumin-degludec }}$ scattering curve. (a) Fit of the rigid-body model (orange) to the experimental data (grey). (b) shows an error-weighted residual plot for the model. (c) The rigid-body model is shown with albumin in grey and the dihexamer in orange. It is superimposed onto the low-resolution $a b$ initio model (light blue). 
The curves overlap well at $q$-values above $0.05 \AA^{-1}\left(\chi^{2}=\right.$ 0.91 ), indicating that common local features are present in both complexes, while the higher concentration curve has higher intensity at lower $q$-values, thus corresponding to a shift in the equilibrium towards larger complexes with larger intramolecular distances.

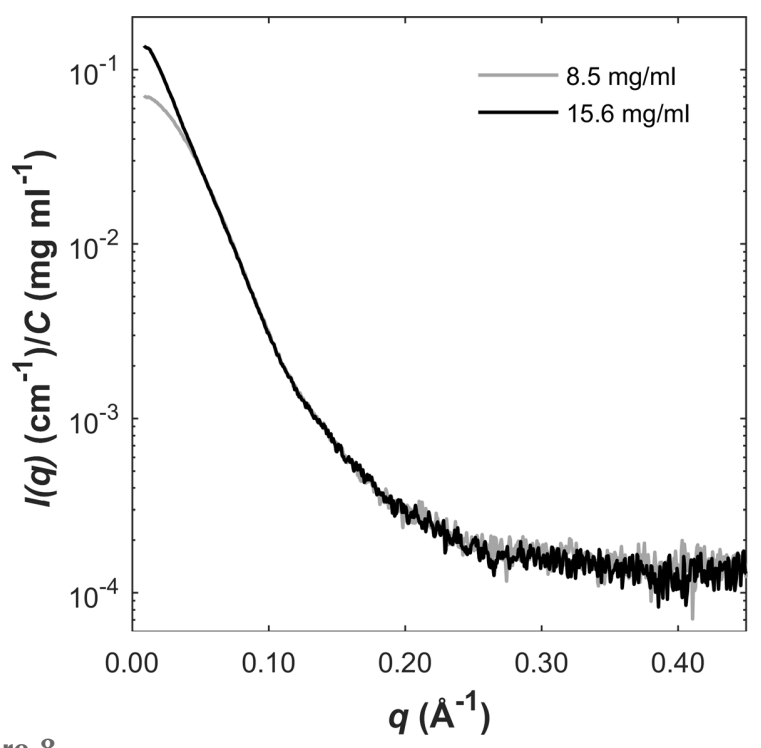

Figure 8

Scattering curves, normalized for concentration, of albumin and detemir mixed in a 1:6 molar ratio with total protein concentrations of 8.5 and $15.6 \mathrm{mg} \mathrm{ml}^{-1}$.
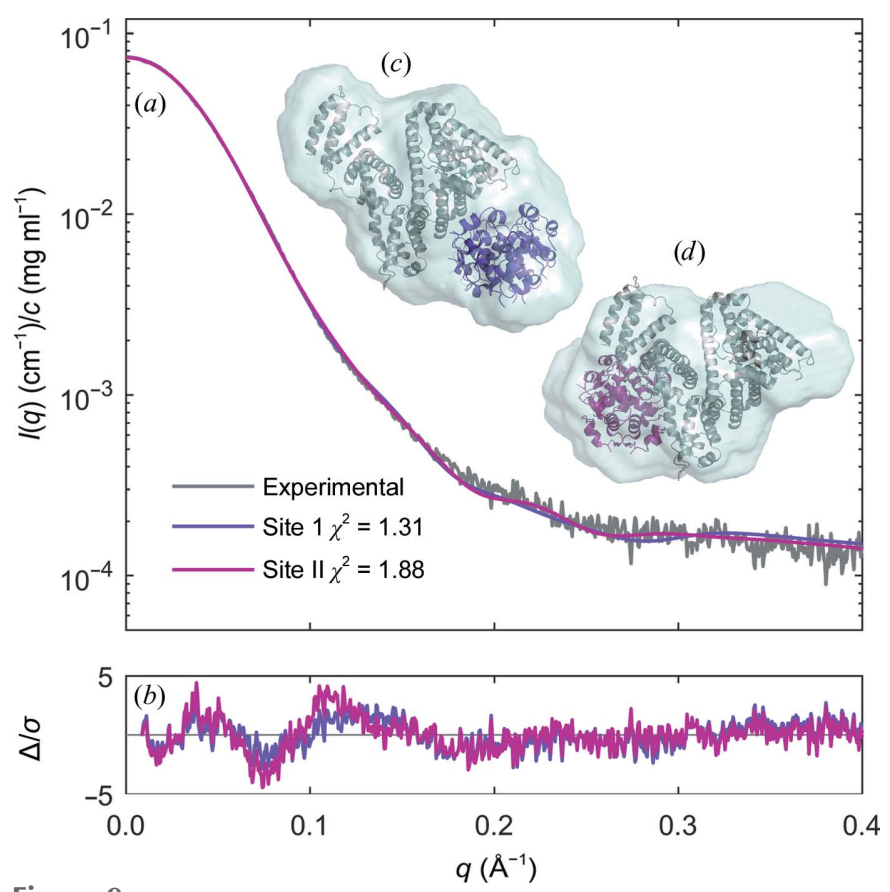

Figure 9

Modelling results of the albumin-hexamer complex based on the $8.5 \mathrm{mg} \mathrm{ml}^{-1}$ albumin-detemir scattering curve. (a) Fit of rigid-body models binding to Sudlow's sites I (purple) and II (magenta) to the experimental data (grey). (b) shows error-weighted residual plots for the models. The rigid-body models are shown in $(c)$ and $(d)$, respectively, with albumin in grey and the same colour coding as in $(a)$ for the hexamers. Both models are superimposed on the low-resolution $a b$ initio model (light blue).
3.4.1. Rigid-body modelling of the albumin-hexamer complex. Ten rigid-body models were generated by SASREF based on the $8.5 \mathrm{mg} \mathrm{ml}^{-1}$ albumin-detemir curve with albumin and a detemir hexamer as input. These ten models could be clustered into two groups based on the binding position on albumin: near Sudlow's site I and near Sudlow's site II. The best model of each cluster and their fits to experimental data $\left(\chi^{2}=1.32\right.$ and $\chi^{2}=1.88$, respectively $)$ are shown in Fig. 9 with the representative ab initio model $(39 \pm 3 \AA)$. The $\chi^{2}$ values of the clusters do not differ very much (Figs. $9 a$ and $9 b$ ) when considering that the conformations of albumin and detemir might change upon binding.

3.4.2. Rigid-body modelling of the albumin-dihexameralbumin complex. Based on the MM from the $15.6 \mathrm{mg} \mathrm{ml}^{-1}$ albumin-detemir SAXS curve, the complex could consist of two albumins and either two hexamers or one dihexamer. Ten rigid-body models were generated with $P 1$ symmetry using two albumins and a dihexamer as input structures, and ten models were generated with $P 2$ symmetry using an albumin and a hexamer as input structures.

The best results with $P 1\left(\chi^{2}=1.01\right)$ and $P 2\left(\chi^{2}=1.12\right)$ symmetry and their fits to the experimental data are presented in Fig. 10, where the rigid-body models are superimposed onto the representative $P 1$ and $P 2$ ab initio models ( $53 \pm 4$ and 55 $\pm 4 \AA$ resolution, respectively). In both rigid-body models detemir forms a dihexamer with one albumin bound to each hexamer and the albumins appear to bind diagonally to the dihexamer.
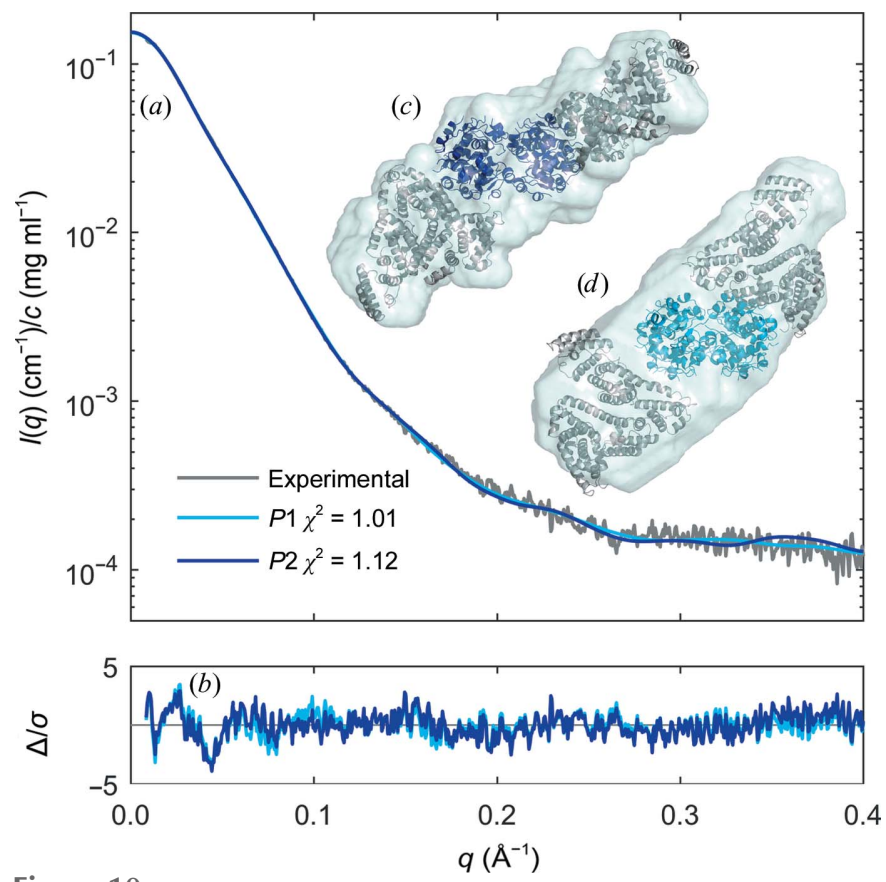

Figure 10

Modelling results of the albumin-dihexamer-albumin complex based on the $15.6 \mathrm{mg} \mathrm{ml}^{-1}$ albumin-detemir scattering curve. (a) Fit of rigid-body models generated with $P 1$ (light blue) and $P 2$ symmetry (blue), respectively, to the experimental data (grey). (b) shows error-weighted residual plots for the models. The rigid-body models are shown in $(c)(P 2$ symmetry) and $(d)$ ( $P 1$ symmetry) with albumins in grey and the same colour-coding as in $(a)$ for the dihexamers. Both models are superimposed onto the low-resolution $a b$ initio model (light blue). 
Table 4

$O L I G O M E R$ results for albumin-detemir samples.

$O L I G O M E R$ results for albumin-detemir samples in the concentration range $1.9-15.6 \mathrm{mg} \mathrm{ml}^{-1}$, showing volume fractions of the species with uncertainties in parentheses and $\chi^{2}$ fits to experimental data.

\begin{tabular}{|c|c|c|c|c|c|c|}
\hline $\begin{array}{l}\text { Concentration } \\
\left(\mathrm{mg} \mathrm{ml}^{-1}\right)\end{array}$ & $\chi^{2}$ & Albumin & Trihexamer & $\begin{array}{l}\text { Albumin- } \\
\text { hexamer }\end{array}$ & $\begin{array}{l}\text { Albumin- } \\
\text { dihexamer }\end{array}$ & $\begin{array}{l}\text { Albumin- } \\
\text { dihexamer- } \\
\text { albumin }\end{array}$ \\
\hline 1.9 & 0.57 & $0.497(7)$ & $0.257(3)$ & $0.25(1)$ & & \\
\hline 4.1 & 0.87 & $0.477(4)$ & $0.246(2)$ & $0.277(5)$ & & \\
\hline 8.5 & 0.77 & $0.184(6)$ & & $0.44(2)$ & $0.36(1)$ & $0.010(2)$ \\
\hline 15.6 & 2.05 & & & & & $1.000(1)$ \\
\hline
\end{tabular}

3.4.3. Analysis of albumin-detemir equilibrium. To assess the equilibria in the albumin-detemir concentration series, OLIGOMER was run. The results are summarized in Table 4 and the fits to the experimental data are shown in Fig. 11.

For the lower concentration samples at 1.9 and $4.1 \mathrm{mg} \mathrm{ml}^{-1}$, we observe an equilibrium between albumin, trihexamer and the albumin-hexamer complex. At $8.5 \mathrm{mg} \mathrm{ml}^{-1}$, the equilibrium shifts towards albumin-dihexamer complexes and the sample consists of albumin, albumin-hexamer and albumin-
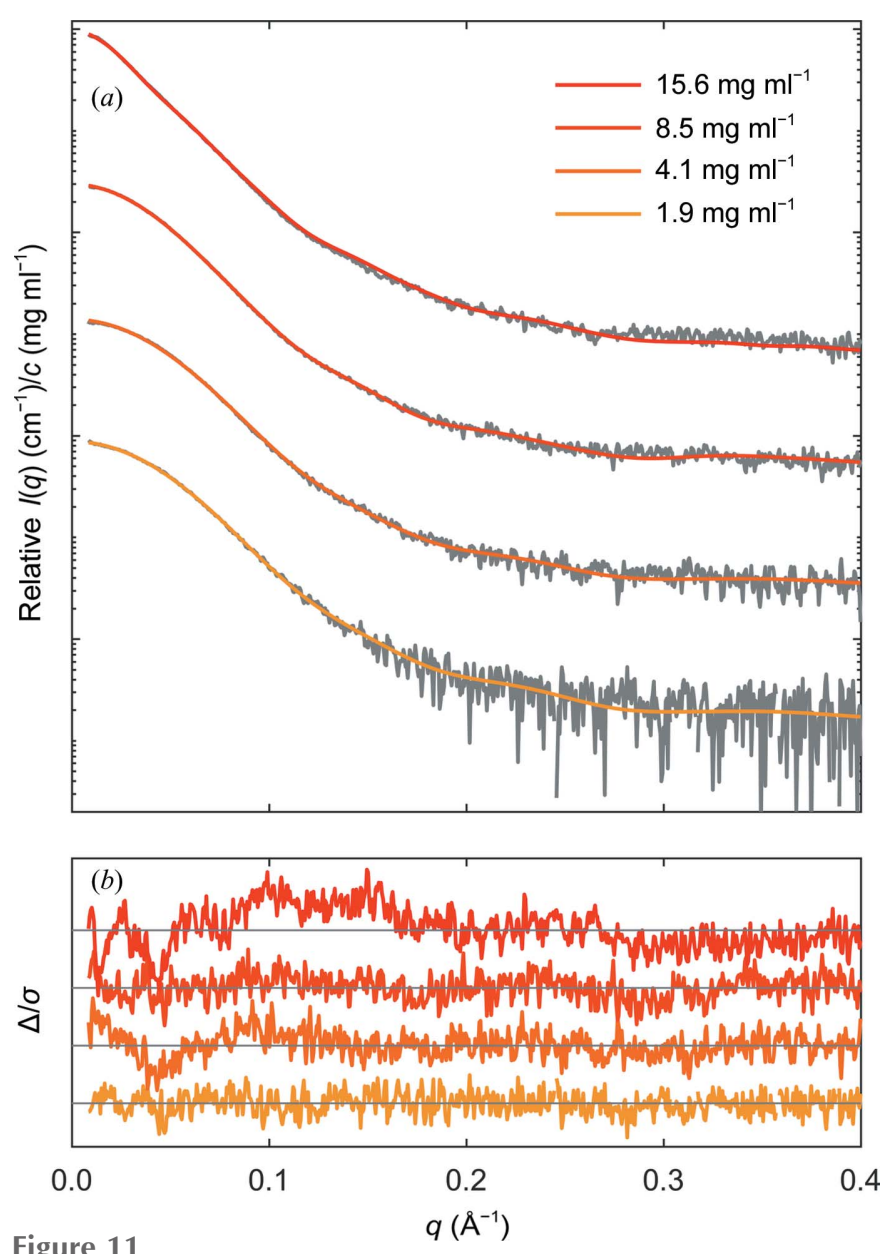

Figure 11

OLIGOMER results for albumin-detemir samples in the concentration range $1.9-15.6 \mathrm{mg} \mathrm{ml}^{-1}$. (a) OLIGOMER fits are plotted (red; darker shades correspond to higher concentrations) with the experimental scattering curves (grey). The scattering curves have been shifted on the $I(q) / c$ axis for clarity. (b) shows an error-weighted residual plot of the fits. dihexamer complexes. At $15.6 \mathrm{mg} \mathrm{ml}^{-1}$, the sample consists entirely of the albumin-dihexamer-albumin complex. For the highest concentration sample at $20.8 \mathrm{mg} \mathrm{m}^{-1}$, the OLIGOMER result does not fit the data (data not shown), which indicates that larger species are needed to describe the curve.

\section{Discussion}

In agreement with previous studies (Steensgaard et al., 2013; Adams et al., 2018; Havelund et al., 2004), we find degludec as a dihexamer in phenol-containing buffer and detemir in a concentration-dependent equilibrium between hexamers, dihexamers, trihexamers and possibly larger multihexamers. We present the first structure of the detemir trihexamer, which has previously only been reported in a study using analytical ultracentrifugation (Adams et al., 2018). Surprisingly, the trihexamer has a bent shape.

For degludec mixed with albumin, DLS data showed that the binding stoichiometry of an albumin-degludec complex was somewhere between 1:6 and 1:12. However, SAXS measurements, both inline SEC-SAXS on a 1:6 albumindegludec mixture and batch measurements on a 1:12 mixture, unambiguously showed a 1:12 complex.

For detemir mixed with albumin, we determined the stoichiometry to be 1:6 by DLS. We succeeded in modelling an albumin-hexamer complex despite the somewhat polydisperse curve, as well as an albumin-dihexamer-albumin complex.

\subsection{Equilibria}

The different complexes of detemir and degludec with albumin can thus be directly linked to their oligomeric states. We propose that detemir and degludec hexamers mixed with albumin exist in the equilibria illustrated in Fig. 12. Degludec alone exists as a dihexamer. When mixed with albumin in a 1:12 ratio, the sample purely consists of albumin-dihexamer complex. Detemir alone exists in an equilibrium with various oligomers. When mixed with albumin, we observe the formation of 1:6, 1:12 and 2:12 complexes, with higher protein concentrations and ionic strengths favouring larger complexes. At the highest protein concentration, however, we observe an increase in the MM beyond the expected value for a 2:12 complex, which could be owing to larger complexes.

The differences between the behaviour of degludec and detemir in solution are solely owing to the different fatty-acid moieties, as the molecules are otherwise identical. The different multihexamerizations indicate that their modes of hexamer-hexamer association are fundamentally different. The driving force of association results from their fatty-acid moieties, as human insulin is normally observed in an equilibrium between monomer, dimer and hexamer (Frankaer $e t$ al., 2017; Jorgensen et al., 2011). While detemir has a C14 fatty acid attached to LysB29, the second-generation product degludec has a C16 dicarboxylic fatty acid attached through a $\gamma$-glutamate linker. The differences in these fatty-acid moieties mean that degludec has a longer fatty-acid chain and 


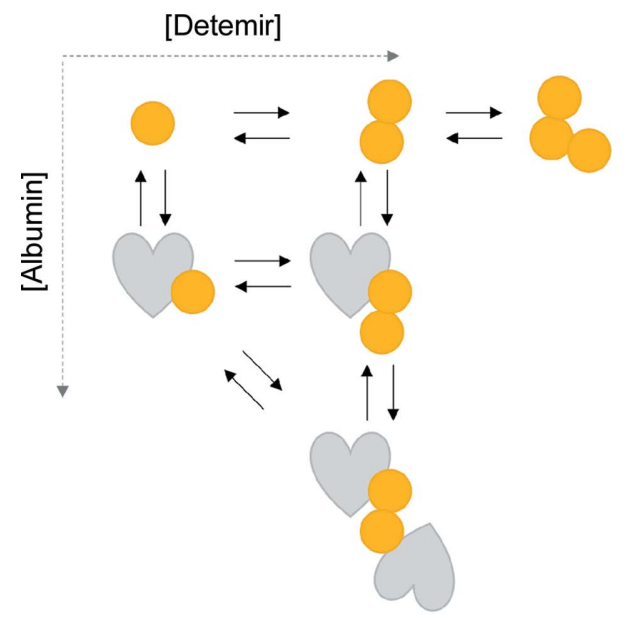

(a)

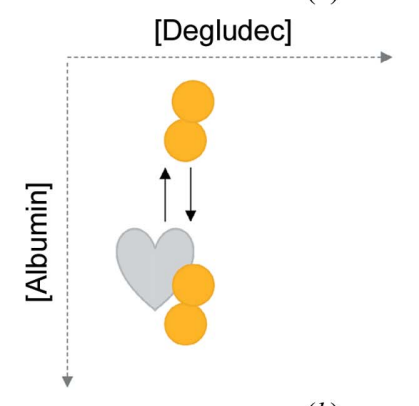

(b)

Figure 12

Proposed equilibria for albumin and $(a)$ detemir and $(b)$ degludec hexamers under the investigated conditions. Albumin is represented as grey hearts and the hexamers as orange circles.

two extra negative charges, allowing different interactions. Therefore, it is likely that the binding of detemir and degludec albumin probably differs significantly at the atomic level.

\section{Conclusion}

Here, we have shown that detemir and degludec exist in different equilibria in phenol-containing buffers and how these equilibria affect their complex formation with albumin. We have presented the solution structures of the detemir trihexamer and of 1:6, 1:12 and 2:12 complexes between albumin and two insulin analogues. The solution structures are the first structures of complexes between albumin and longacting insulin analogues to be presented.

\section{Acknowledgements}

We would like to acknowledge MAX IV Laboratory and DESY Hamburg for providing beam time for the SAXS experiments. Albumedix Ltd is acknowledged for providing proteins (including Recombumin ${ }^{\circledR}$ Elite and Alpha) for the experiments and for access to their DLS plate reader.

\section{Funding information}

The following funding is acknowledged: Department of Chemistry, Technical University of Denmark (scholarship to
Line A. Ryberg); DANSCATT (The Danish Agency for Science, Technology and Innovation; bursary to Line A. Ryberg, Pernille Sønderby, Günther H. J. Peters, Pernille Harris).

\section{References}

Adams, G. G., Alzahrani, Q., Jiwani, S. I., Meal, A., Morgan, P. S., Coffey, F., Kok, S., Rowe, A. J., Harding, S. E., Chayen, N. \& Gillis, R. B. (2017). Sci. Rep. 7, 7287.

Adams, G. G., Meal, A., Morgan, P. S., Alzahrani, Q. E., Zobel, H., Lithgo, R., Kok, M. S., Besong, D. T. M., Jiwani, S. I., Ballance, S., Harding, S. E., Chayen, N. \& Gillis, R. B. (2018). PLoS One, 13, e0195010.

Agers $\emptyset$, H., Jensen, L. B., Elbrønd, B., Rolan, P. \& Zdravkovic, M. (2002). Diabetologia, 45, 195-202.

Ascenzi, P. \& Fasano, M. (2010). Biophys. Chem. 148, 16-22.

Blanchet, C. E., Spilotros, A., Schwemmer, F., Graewert, M. A., Kikhney, A., Jeffries, C. M., Franke, D., Mark, D., Zengerle, R., Cipriani, F., Fiedler, S., Roessle, M. \& Svergun, D. I. (2015). J. Appl. Cryst. 48, 431-443.

Bukrinski, J. T., Sønderby, P., Antunes, F., Andersen, B., Schmidt, E. G. W., Peters, G. H. J. \& Harris, P. (2017). Biochemistry, 56, 48604870.

Chaudhury, C., Brooks, C. L., Carter, D. C., Robinson, J. M. \& Anderson, C. L. (2006). Biochemistry, 45, 4983-4990.

Chaudhury, C., Mehnaz, S., Robinson, J. M., Hayton, W. L., Pearl, D. K., Roopenian, D. C. \& Anderson, C. L. (2003). J. Exp. Med. 197, 315-322.

Ciszak, E. \& Smith, G. D. (1994). Biochemistry, 33, 1512-1517.

Curry, S., Mandelkow, H., Brick, P. \& Franks, N. (1998). Nature Struct. Biol. 5, 827-835.

Danne, T., Lüpke, K., Walte, K., Von Schuetz, W. \& Gall, M.-A. (2003). Diabetes Care, 26, 3087-3092.

Deacon, C. F. (2009). Vasc. Heal. Risk Manag. 5, 199-211.

European Medicines Agency (2012). CHMP Assessment Report: Tresiba. London: European Medicines Agency. https:// www.ema.europa.eu/documents/assessment-report/tresiba-epar-publicassessment-report_en.pdf.

Fanali, G., di Masi, A., Trezza, V., Marino, M., Fasano, M. \& Ascenzi, P. (2012). Mol. Aspects Med. 33, 209-290.

Frankaer, C. G., Sønderby, P., Bang, M. B., Mateiu, R. V., Groenning, M., Bukrinski, J. \& Harris, P. (2017). J. Struct. Biol. 199, 27-38.

Franke, D., Petoukhov, M. V., Konarev, P. V., Panjkovich, A., Tuukkanen, A., Mertens, H. D. T., Kikhney, A. G., Hajizadeh, N. R., Franklin, J. M., Jeffries, C. M. \& Svergun, D. I. (2017). J. Appl. Cryst. 50, 1212-1225.

Franke, D. \& Svergun, D. I. (2009). J. Appl. Cryst. 42, 342-346.

Frederiksen, T. M., Sønderby, P., Ryberg, L. A., Harris, P., Bukrinski, J. T., Scharff-Poulsen, A. M., Elf-Lind, M. N. \& Peters, G. H. (2015). Biophys. J. 109, 1202-1213.

Gasteiger, E., Gattiker, A., Hoogland, C., Ivanyi, I., Appel, R. D. \& Bairoch, A. (2003). Nucleic Acids Res. 31, 3784-3788.

Gasteiger, E., Hoogland, C., Gattiker, A., Duvaud, S., Wilkins, M. R., Appel, R. D. \& Bairoch, A. (2005). The Proteomics Protocols Handbook, edited by J. M. Walker, pp. 571-607. Totowa: Humana Press.

Ha, C.-E. \& Bhagavan, N. V. (2013). Biochim. Biophys. Acta, 1830, 5486-5493.

Hanlon, A. D., Larkin, M. I. \& Reddick, R. M. (2010). Biophys. J. 98, 297-304.

Havelund, S., Plum, A., Ribel, U., Jonassen, I., Vølund, A., Markussen, J. \& Kurtzhals, P. (2004). Pharm. Res. 21, 1498-1504.

Heise, T., Nosek, L., Bøttcher, S. G., Hastrup, H. \& Haahr, H. (2012). Diabetes Obes. Metab. 14, 944-950.

Jonassen, I., Havelund, S., Hoeg-Jensen, T., Steensgaard, D. B., Wahlund, P.-O. \& Ribel, U. (2012). Pharm. Res. 29, 2104-2114. 
Jorgensen, L., Bennedsen, P., Hoffmann, S. V., Krogh, R. L., Pinholt, C., Groenning, M., Hostrup, S. \& Bukrinsky, J. T. (2011). Eur. J. Pharm. Sci. 42, 509-516.

Kieffer, J. \& Wright, J. P. (2013). Powder Diffr. 28, S339-S350.

Knudsen, L. B., Nielsen, P. F., Huusfeldt, P. O., Johansen, N. L., Madsen, K., Pedersen, F. Z., Thøgersen, H., Wilken, M. \& Agers $\varnothing$, H. (2000). J. Med. Chem. 43, 1664-1669.

Konarev, P. V., Volkov, V. V., Sokolova, A. V., Koch, M. H. J. \& Svergun, D. I. (2003). J. Appl. Cryst. 36, 1277-1282.

Kurtzhals, P., Heise, T., Strauss, H. M., Bottcher, S. G., Granhall, C., Haahr, H. \& Jonassen, I. (2011). Diabetologia, 54, S426.

Labrador, A., Cerenius, Y., Svensson, C., Theodor, K. \& Plivelic, T. (2013). J. Phys. Conf. Ser. 425, 072019.

Lau, J., Bloch, P., Schäffer, L., Pettersson, I., Spetzler, J., Kofoed, J., Madsen, K., Knudsen, L. B., McGuire, J., Steensgaard, D. B., Strauss, H. M., Gram, D. X., Knudsen, S. M., Nielsen, F. S., Thygesen, P., Reedtz-Runge, S. \& Kruse, T. (2015). J. Med. Chem. 58, 7370-7380.

Mylonas, E. \& Svergun, D. I. (2007). J. Appl. Cryst. 40, s245-s249.

Olsen, H. B. \& Kaarsholm, N. C. (2000). Biochemistry, 39, $11893-$ 11900.

Peters, T. (1985). Adv. Protein Chem. 37, 161-245.

Petoukhov, M. V., Franke, D., Shkumatov, A. V., Tria, G., Kikhney, A. G., Gajda, M., Gorba, C., Mertens, H. D. T., Konarev, P. V. \& Svergun, D. I. (2012). J. Appl. Cryst. 45, 342-350.

Petoukhov, M. V. \& Svergun, D. I. (2005). Biophys. J. 89, 1237-1250.

Petoukhov, M. V. \& Svergun, D. I. (2006). Eur. Biophys. J. 35, 567576.

Petoukhov, M. V. \& Svergun, D. I. (2015). Acta Cryst. D71, 10511058.

Seested, T., Havelund, S., Jonassen, I. B., Hoeg-Jensen, T., Pyke, C., Kapor, J. \& Nishimura, E. (2012). Can. J. Diab. 36, S61.
Sleep, D. (2014). Expert Opin. Drug Deliv. 12, 793-812.

Sleep, D., Cameron, J. \& Evans, L. R. (2013). Biochim. Biophys. Acta, 1830, 5526-5534.

Smith, G. D., Ciszak, E., Magrum, L. A., Pangborn, W. A. \& Blessing, R. H. (2000). Acta Cryst. D56, 1541-1548.

Smith, G. D., Pangborn, W. A. \& Blessing, R. H. (2003). Acta Cryst. D59, 474-482.

Steensgaard, D. B., Schluckebier, G., Strauss, H. M., Norrman, M., Thomsen, J. K., Friderichsen, A. V., Havelund, S. \& Jonassen, I. (2013). Biochemistry, 52, 295-309.

Sudlow, G., Birkett, D. J. \& Wade, D. N. (1975). Mol. Pharmacol. 11, 824-832.

Sugio, S., Kashima, A., Mochizuki, S., Noda, M. \& Kobayashi, K. (1999). Protein Eng. 12, 439-446.

Svergun, D., Barberato, C. \& Koch, M. H. J. (1995). J. Appl. Cryst. 28, 768-773.

Svergun, D. I. (1992). J. Appl. Cryst. 25, 495-503.

Svergun, D. I. (1999). Biophys. J. 76, 2879-2886.

Trewhella, J., Duff, A. P., Durand, D., Gabel, F., Guss, J. M., Hendrickson, W. A., Hura, G. L., Jacques, D. A., Kirby, N. M., Kwan, A. H., Pérez, J., Pollack, L., Ryan, T. M., Sali, A., Schneidman-Duhovny, D., Schwede, T., Svergun, D. I., Sugiyama, M., Tainer, J. A., Vachette, P., Westbrook, J. \& Whitten, A. E. (2017). Acta Cryst. D73, 710-728.

Tuukkanen, A. T., Kleywegt, G. J. \& Svergun, D. I. (2016). IUCrJ, 3, 440-447.

Valentini, E., Kikhney, A. G., Previtali, G., Jeffries, C. M. \& Svergun, D. I. (2015). Nucleic Acids Res. 43, D357-D363.

Volkov, V. V. \& Svergun, D. I. (2003). J. Appl. Cryst. 36, 860-864.

Whittingham, J. L., Havelund, S. \& Jonassen, I. (1997). Biochemistry, 36, 2826-2831.

Yang, F., Zhang, Y. \& Liang, H. (2014). Int. J. Mol. Sci. 15, 3580-3595. 